Artikel Penelitian

Vol 7 No. 2, Oktober 2018

ISSN $2460-8742$

http://journal.unair.ac.id/ORTHO@journal-orthopaedi-and-traumatology-surabaya-media-104.html

\title{
RELATIONSHIP OF ACL INJURY WITH POSTERIOR TIBIAL SLOPE, INTERCONDYLAR NOTCH WIDTH RATIO, AGE, AND SEX
}

\author{
Boby Harul Priono ${ }^{1 *}$, Ghuna Arioharjo Utoyo ${ }^{2}$, Yoyos Dias Ismiarto ${ }^{2}$ \\ ${ }^{1}$ Resident of Orthopedic and Traumatology Department, Universitas Padjadjaran/Dr.Hasan \\ Sadikin General Hospital Bandung \\ ${ }^{2}$ Staff of Orthopedic and Traumatology Department, Universitas Padjadjaran/Dr.Hasan \\ Sadikin General Hospital Bandung \\ *Corresponding Author: Boby Harul Priono, Resident of Orthopaedic and Traumatology \\ Department, Universitas Padjadjaran/Dr.Hasan Sadikin General Hospital Bandung, Jl. Pasteur \\ No. 38, Bandung \\ E-mail: bobyharulpriono@gmail.com
}

\begin{abstract}
ABSTRAK
Sudut posterior tibial slope (PTS) berpengaruh pada translasi tibia terhadap femur, sedang rasio Intercondylar Notch Width (INW) memberikan ruang gerak bagi ACL saat fleksiekstensi lutut. Penelitian ini bertujuan untuk memperlihatkan faktor-faktor yang dapat meningkatkan resiko terjadinya cedera ACL, sehingga pencegahan pada atlet yang memiliki resiko tinggi dapat dilakukan dan sebagai acuan awal nilai normal bagi populasi orang Indonesia. Penelitian ini dilakukan pada 20 pasien yang telah X-ray, MRI lutut dan prosedur athroskopi antara bulan Agustus 2016 sampai Maret 2017. Dibagi menjadi 2 kelompok; kelompok yang memiliki cedera ACL $(\mathrm{n}=10)$ dan kelompok yang tidak memiliki cedera ACL $(\mathrm{n}=10)$. Data pasien dinilai dengan Protactor app dan Ruler app. Dari analisis data, didapatkan nilai sudut PTS dengan cedera ACL $(14,4 \mathrm{SD} \pm 3,5)$ lebih tinggi daripada non cedera ACL $(10,1 \mathrm{SD} \pm 2.6)$. Nilai $\mathrm{p}$ uji t-test untuk sudut PTS adalah $0,04645(\mathrm{p}<0,05)$, sedangkan untuk rasio INW 0,18545 ( $p>0,05)$. Nilai $p$ uji chi square untuk jenis kelamin adalah $0,32114(p>0,05)$ dan nilai $\mathrm{p}$ uji Z-score untuk umur 0,2113 ( $\mathrm{p}>0,05)$. Nilai sudut PTS pada populasi ini ialah $5^{\circ}$ $19^{\circ}$ dengan rata-rata $12,2^{\circ}$. Sudut PTS berpengaruh meningkatkan resiko terjadi cedera ACL, semakin besar sudut PTS, semakin besar resiko cedera ACL yang mungkin akan didapat. Rasio INW, jenis kelamin dan umur tidak memberikan hasil yang signifikan atas peningkatan terjadinya cedera ACL.
\end{abstract}

Kata kunci: Cedera Anterior Cruciate Ligamen, sudut Posterior Tibial Slope, rasio Intercondylar Notch Width, usia, jenis kelamin

\begin{abstract}
Posterior tibial slope (PTS) has been proposed as a potential risk factor for ACL injury; however, studies that examined this relationship have provided inconclusive and sometimes contradictory results. Further characterization of this relationship may enable the medical community to identify individuals at greater risk for ACL injury and possibly characterize an anatomic target during surgical reconstruction. Medical records of 20 patients who underwent MRI of the knee and athroscopy procedure between August 2016 and March 2017 were reviewed. Patients were separated into 2 groups: a study group of those subjects who had undergone surgery for ACL injury $(n=10)$ and a control group of patients diagnosed without ACL Injury $(n=10)$. Demographic data were collected, and MRI images from both groups were analyzed using protactor android imaging software to obtain PTS measurements. Data then analyzed using SPSS v20. Data analysis demonstrated that the ACL injury group had significantly greater values for PTS (14.4 SD \pm 3.5$)$ compared with controls $(10.1 \mathrm{SD} \pm 2.6)$. After stepwise elimination of non significant variables, the final $t$ test independent determined
\end{abstract}


that PTS ( $\mathrm{p}$ value $0.08 ; \mathrm{p}<0.1$ ) had statistically significant relationships with ACL injury. INW ratio, age, and sex were not demonstrated to be significant predictors of ACL injury in this final model. This study showed a relationship between increased PTS and ACL injury, which corroborates the findings of previously published studies. INW ratio, sex, and age showed no significant relationship with ACL injury.

Keywords: Anterior Cruciate Ligament injury, posterior tibial slope, Intercondylar Notch Width ratio, age, sex

\section{PENDAHULUAN}

Cedera anterior cruciate ligament (ACL) termasuk cedera yang sering terjadi terutama pada atlet. Angka kejadian cedera ACL sekitar 30-78 kasus dalam 100.000 orang. ${ }^{1,2}$ Penyebab cedera ACL karena adanya mekanisme trauma dengan posisi lutut rotasi, hiperekstensi (non-pivoting injury) atau karena kontraksi dari otot quadriseps femoris secara tiba-tiba. ${ }^{3,4} \mathrm{ACL}$ terdiri dari 2 anyaman, anteromedial dan posterolateral. ACL merupakan stabilitas utama untuk anterior translasi dari tibia. Putusnya ACL menyebabkan lutut tidak dapat bekerja secara optimal, walau telah ada prosedur rekontruksi ACL per arthroskopi dengan hasil yang memuaskan, penyembuhan pasien rata-rata 6-8 bulan pascaoperasi untuk kembali latihan. ${ }^{5}$ Hal tersebut membuat produktivitas atlet terganggu. Pencegahan terjadinya cedera ACL dengan cara identifikasi berbagai faktor resiko yang meningkatkan terjadinya cedera menjadi titik penting untuk mengurangi angka kejadian cedera ACL. Terdapat penelitian yang menunjukkan bahwa rasio INW menjadi salah satu resiko terjadinya cedera ACL pada atlet. ${ }^{6}$ Todd $e t$ al. mengatakan bahwa parameter terpenting untuk terjadinya cedera ACL adalah intercondylar notch. Pada studi morfometrik sendi lutut, notch width ratio dan notch shape ratio sering digunakan untuk mendeteksi adanya kemungkinan impingement ACL., ${ }^{2,7}$ Sebelumnya, belum pernah dilakukan penelitian mengenai PTS dan INW di Indonesia.

Stabilitas dari lutut ditunjang oleh tulang dan ligamen. Posterior Tibial Slope termasuk dalam stabilitas anteroposterior. Hal tersebut dikarenakan PTS mempengaruhi seberapa besar translasi ke anterior dari tibia terhadap femur. Peningkatan PTS sering dihubungkan dengan meningkatnya ruptur ACL. ${ }^{8}$ Pengukuran medial atau lateral slope tidak memberikan perbedaan pada pemeriksaan. $^{9,10}$ Penilaian sudut PTS dengan cara X-ray knee lateral view, sudut yang dibentuk antara garis perpendicular longitudinal aksis dari tibia dan tangensial dengan medial dan lateral plateau. Variasi pengukuran aksis ini telah dilaporkan antara 
Artikel Penelitian

Vol 7 No. 2, Oktober 2018

ISSN 2460-8742

http://journal.unair.ac.id/ORTHO@journal-orthopaedi-and-traumatology-surabaya-media-104.html

$4^{\circ}-14^{\circ} .{ }^{11,12}$ Penilaian ini biasanya dilakukan

secara komputerisasi dan banyak rumah sakit di Indonesia yang belum memiliki perangkat ini.

Penggunaan perangkat handphone android saat ini menjadi hal yang sangat populer di dunia. Protactor android dan Ruler android software dapat mempermudah penilaian berbagai faktor resiko yang mempengaruhi cedera ACL secara faktual. Diharapkan penelitian ini dapat digunakan sebagai nilai awal PTS serta INW pada orang Indonesia.

\section{METODOLOGI PENELITIAN}

Penelitian ini bersifat retrosprektif. Kriteria pemilihan pasien ialah pasien dilakukan MRI lutut dan X-ray lutut AP/Lateral sebagai pemeriksaan penunjang dari keluhan. Lalu dilakukan prosedur athroskopi lutut sebagai diagnosa pasti dan terapi bagi pasien. Kriteria eksklusi penelitian ini yaitu adanya riwayat trauma (patah tulang, kerusakan ligament) pada lutut sebelumnya. Data pasien dikumpulkan dari rekam medis, data X-ray dan MRI lutut sejak bulan agustus 2016 sampai bulan maret 2017. Didapatkan 20 pasien yang terdiri dari 14 pria dan 6 wanita, dengan ratarata umur 22,2 tahun. Kemudian, MRI dan X-ray lutut dinilai sudut PTS dan rasio INW.

Sudut PTS dinilai dari MRI potongan sagittal, atau X-ray lateral view. Sudut PTS dibentuk antara garis perpendicular dari aksis tibia dengan garis dari medial/lateral slope tibia. ${ }^{13,14}$ Penilaian ini dengan protactor android sofware. Sedangkan rasio INW adalah rasio lebarnya intercondylar notch femur terhadap condyle femur. ${ }^{15}$ Penilaian ini dengan menggunakan program Ruler android.

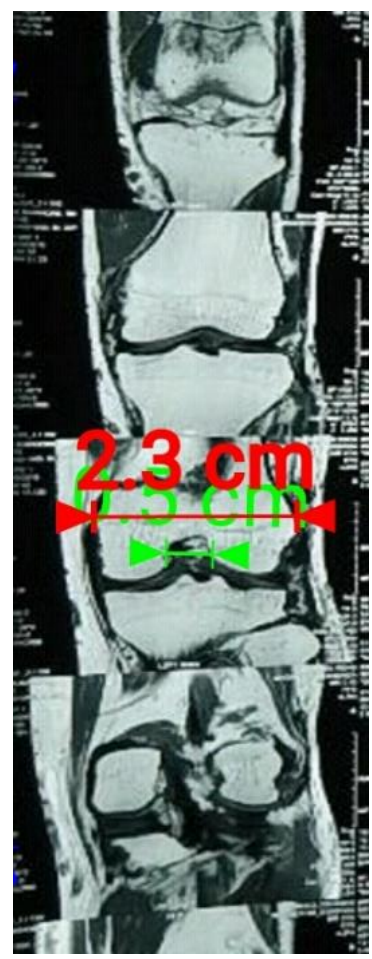

Gambar 1. Rasio INW

$\mathrm{X}$-ray lutut lateral view dilakukan dengan $30^{\circ}$ fleksi. Seluruh X-ray dilakukan di bagian radiologi RS. Hasan Sadikin Bandung. 


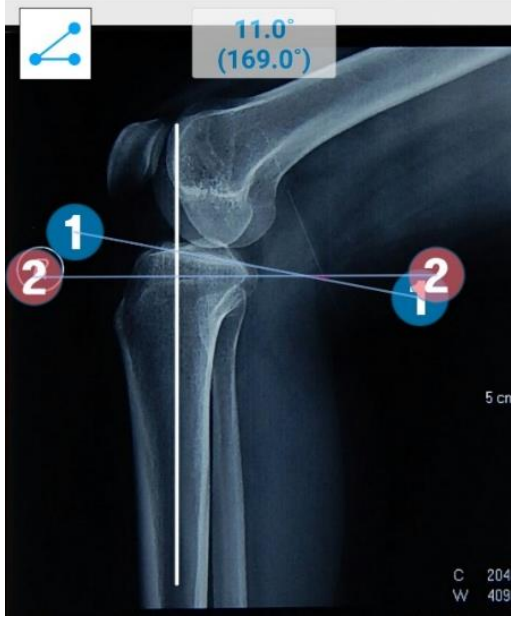

Gambar 2. Sudut PTS

Pasien terbagi 2 kelompok,

kelompok pertama adalah pasien yang mengalami cedera ACL dan kelompok kedua yang tidak mengalami cedera ACL. Seluruh pasien dilakukan X-ray lutut, MRI lutut dan prosedur athroskopi lutut. Hasil penilaian kemudian dinilai dengan menggunakan SPSS v.20 for Windows software (IBM). Uji normalitas dengan menggunakan tes kolmogrov-smirnov. Kemudian dilakukan analisa stastistik dengan menggunakan t-test jika distribusi variabel normal dan Mann-Whitney test jika distribusi variabel tidak normal. Dengan nilai $\mathrm{p}<0,05$, untuk hasil signifikan.

\section{HASIL DAN PEMBAHASAN}

Karakteristik pasien dengan cedera ACL dan hasil penilaian diperlihatkan pada tabel 1. Pasien termuda ialah 18 tahun dan tertua adalah 35 tahun. Dengan berbagai jenis olahraga penyebabnya, seperti sepakbola, basket, dan lain-lain.
Tabel 1. Distribusi pasien dengan cedera ACL

\begin{tabular}{cccccc}
\hline Sex & Age & $\begin{array}{c}\text { Condyle } \\
\text { Length } \\
\text { (cm) }\end{array}$ & $\begin{array}{c}\text { INW } \\
\text { (cm) }\end{array}$ & $\begin{array}{c}\text { INW } \\
\text { Ratio }\end{array}$ & PTS \\
\hline M & 23 & 2,9 & 0,5 & 0,189 & 12,7 \\
F & 28 & 2,9 & 0,7 & 0,236 & 15,4 \\
M & 35 & 3,3 & 0,8 & 0,244 & 12,2 \\
M & 22 & 4,5 & 0,7 & 0,157 & 11,1 \\
M & 30 & 2,9 & 0,5 & 0,172 & 19,4 \\
M & 29 & 2,0 & 0,3 & 0,144 & 14,4 \\
M & 24 & 2,6 & 0,5 & 0,192 & 18,2 \\
M & 30 & 2,9 & 0,7 & 0,190 & 14,8 \\
M & 23 & 3,0 & 0,7 & 0,237 & 17,7 \\
F & 18 & 2,8 & 0,5 & 0,181 & 8,1 \\
\hline
\end{tabular}

Tabel 2 memperlihatkan hasil dari penilaian terhadap pasien tanpa cedera ACL. Penyebab cedera pada lutut berbagai penyebabnya seperti jatuh dari tangga, sepeda atau badminton. Pasien paling muda ialah 21 tahun dan tertua ialah 33 tahun.

Tabel 2. Distribusi pasien dengan Noncedera ACL

\begin{tabular}{cccccc}
\hline Sex & Age & $\begin{array}{c}\text { Condyle } \\
\text { Length } \\
\text { (cm) }\end{array}$ & $\begin{array}{c}\text { INW } \\
(\mathbf{c m})\end{array}$ & $\begin{array}{c}\text { INW } \\
\text { Ratio }\end{array}$ & PTS \\
\hline F & 21 & 2,4 & 0,5 & 0,201 & 9,6 \\
F & 33 & 1,8 & 0,4 & 0,243 & 12,8 \\
M & 21 & 2,3 & 0,5 & 0,203 & 5,1 \\
M & 25 & 4,1 & 0,9 & 0.215 & 13,2 \\
F & 27 & 2,7 & 0,6 & 0,207 & 13,3 \\
M & 30 & 2,2 & 0,5 & 0,213 & 9,1 \\
M & 28 & 2,8 & 0,7 & 0,247 & 10,5 \\
M & 24 & 2,8 & 0,6 & 0,213 & 8,2 \\
F & 21 & 2,5 & 0,5 & 0,224 & 10,8 \\
M & 32 & 3,7 & 0,8 & 0,215 & 8,3 \\
\hline
\end{tabular}

Tabel 3. Hasil Statistik PTS (t-test)

\begin{tabular}{lrrr}
\hline \multirow{2}{*}{ Variabel } & \multicolumn{2}{c}{ Group } & \\
\cline { 2 - 3 } & Group 1 & Group 2 & \\
\cline { 2 - 3 } P Value \\
\hline PTS & $\mathrm{N}=10$ & $\mathrm{~N}=\mathbf{1 0}$ & \\
\hline
\end{tabular}


Artikel Penelitian

Vol 7 No. 2, Oktober 2018

ISSN 2460-8742

http://journal.unair.ac.id/ORTHO@journal-orthopaedi-and-traumatology-surabaya-media-104.html

\begin{tabular}{lcc} 
Mean \pm SL & $14.4 \pm 3.492$ & $10.09 \pm 3.932$ \\
Median & 14.6 & 10.05 \\
Range & $12.23-16.56$ & $6.15-14.22$ \\
(min- & & \\
max) & & \\
\hline
\end{tabular}

Tabel 4. Hasil Rasio INW (t-test)

\begin{tabular}{lccc}
\hline \multirow{3}{*}{ Variabel } & \multicolumn{2}{c}{ Group } & \\
\cline { 2 - 3 } & Group 1 & Group 2 & \multirow{2}{*}{ P Value } \\
\cline { 2 - 3 } & $\mathbf{N}=\mathbf{1 0}$ & $\mathbf{N}=\mathbf{1 0}$ & \\
\hline INW & & & $\mathbf{0 . 1 8 5 4 3}$ \\
\hline Mean \pm SD & $0.971 \pm$ & $0.103 \pm$ & \\
& 0.102 & 0.112 & \\
Median & 0.272 & 0.215 & \\
\hline
\end{tabular}

Tabel 5. Perhitungan untuk umur dan jenis

\begin{tabular}{llll}
\multicolumn{3}{c}{ kelamin. } \\
\hline & $\begin{array}{l}\text { Chi } \\
\text { Square }\end{array}$ & $\begin{array}{l}\text { Z- } \\
\text { Score }\end{array}$ & Conclusion \\
\hline Sex & $p=$ & & Not \\
& 0,32114 & & significant \\
Age & & $p=$ & Not \\
& & 0,2113 & Significant \\
\hline
\end{tabular}

Nilai normal untuk posterior tibial slope untuk setiap populasi, sampai saat ini belum ada nilai referensi. Akan tetapi, beberapa laporan menyebutkan variasi tiap ras dan kisaran perbedaan nilai antara 0-18 derajat. Posterior tibial slope dapat dinilai dengan berbagai cara, seperti penilaian langsung pada kadaver, X-ray, MRI dan CTscan. Brazier et al. mendeskripsikan penilaian sudut PTS yang dapat digunakan. Menurutnya, garis yang diperlukan ialah tibial proximal anatomical axis (TPAA); Tibial Shaft anatomic axis (TSAA) dan Fibular Shaft Axis (FSA). Dari penelitian tersebut didapatkan bahwa pengunaan TSAA memiliki reliabilitas yang lebih daripada yang lain, sehingga cara yang paling ideal untuk menilai sudut PTS ialah perpendicular terhadap TSAA. Untuk penilaian ini membutuhkan X-ray lutut lateral view, dan ini tidak diambil secara rutin. TPAA tidak tepat untuk menggambarkan mekanikal aksis tapi hanya memberikan perkiraan sudut PTS. ${ }^{13}$ Dengan alasan ini, maka kami melakukan penilaian sudut PTS dengan menggunakan TSAA pada studi ini.

Pada penelitian ini, seluruh pasien adalah warga negara Indonesia etnis Sunda, dimana sampai saat ini belum ada nilai normal sudut PTS untuk populasi orang Indonesia. Didapatkan variasi PTS antara $5^{\circ}-19^{\circ}$ dengan rata-rata $12,2^{\circ}$. Rata-rata sudut PTS pria lebih tinggi daripada wanita. Hal ini berbanding terbalik dari penelitian Hashemi et al. yang menemukan PTS wanita lebih tinggi daripada PTS pria. ${ }^{16}$ Yoga dan Suresh menemukan rata-rata preoperatif untuk nilai sudut PTS pada populasi Malaysia sebesar $10,0^{\circ} ; 9,9^{\circ}$ pada populasi orang Cina dan $8,8^{\circ}$ pada populasi orang India $^{17}$, sementara Yue et al. memberikan data rata-rata PTS populasi orang Cina adalah $5,1 \pm 2,3^{\circ}{ }^{14}$ Haddad et al. memberikan data rata PTS $4,2^{\circ}$ pada populasi orang kulit putih, $7,9^{\circ}$ pada orang Asia dan $6,0^{\circ}$ pada orang Afrokaribia/Eropa. ${ }^{18}$

Pada studi ini didapatkan sudut PTS yang meningkat pada kasus cedera ACL 
Artikel Penelitian

Vol 7 No. 2, Oktober 2018

ISSN 2460-8742

http://journal.unair.ac.id/ORTHO@journal-orthopaedi-and-traumatology-surabaya-media-104.html

$(\mathrm{p}<0,05)$. Hasil ini sesuai dengan penelitian sebelumnya populasi muda. ${ }^{19}$ Namun, sistematik review pada tahun 2015 menyimpulkan bahwa peningkatan resiko terjadinya cedera ACL dipengaruhi berbagai faktor resiko, dimana lateral atau medial PTS tidak memberikan efek peningkatan resiko terjadinya cedera ACL. ${ }^{20}$ Hal tersebut dapat dijelaskan karena adanya faktor biomekanik dan kinematik implikasi dari peningkatan tibial slope, seperti adanya peningkatan regangan pada ACL karena adanya translasi anterior dari tibia.

Rasio INW pada penelitian ini menyimpulkan bahwa tidak ada peningkatan resiko terjadinya ACL dengan peningkatan INW rasio, hal ini berbeda dengan penelitian oleh Simon et al yang menemukan bahwa adanya penyempitan INW pada pasien yang memiliki cedera ACL. ${ }^{15}$ Intercondylar notch yang sempit menyebabkan pergerakan dari ACL akan terjadi friksi pada atap intercondylar notch sehingga dapat memudahkan terjadinya cedera ACL. Sedangkan rasio INW tidak menggambarkan lebar atau sempitnya celah intercondylar notch. Pada penelitian lain menyebutkan intercondylar notch kurang dari 0,26 inch $(6,6 \mathrm{~mm})$ akan menyebabkan peningkatan resiko cedera ACL. ${ }^{21}$ Namun, nilai stenosis dari intercondylar notch belum mencapai satu kesimpulan. Al-saeed mengatakan stenosis INW yang mengakibatkan peningkatan cedera ACL bila nilainya kurang dari $0,269 .{ }^{22}$ Diperlukan populasi yang lebih luas untuk menyimpulkan pengaruh INW terhadap cedera ACL terutama pada populasi orang Indonesia. Sedangkan untuk gender dan usia, tidak ditemukan adanya perbedaan signifikan antara pria dan wanita untuk terjadinya cedera ACL $(p>0,05)$. Hal ini sesuai dengan penelitian di Perancis, dengan sampel 298 atlet yang menyimpulkan bahwa kedua faktor tersebut tidak memberikan peningkatan resiko cedera $\mathrm{ACL}^{23}$ Dari penelitian ini didapatkan nilai rata-rata PTS $12,245^{\circ}$ dan INW $0,605 \mathrm{~cm}$ yang dapat digunakan sebagai data acuan awal nilai PTS dan INW pada orang Indonesia.

\section{KESIMPULAN DAN SARAN}

Pada penelitian ini didapatkan ratarata sudut PTS adalah $12,2^{\circ}$. Sudut PTS yang tinggi menyebabkan peningkatan regangan ACL saat pergerakan lutut sehingga resiko terjadinya cedera ACL meningkat. Rasio INW tidak menggambarkan stenosis intercondylar notch. Jenis kelamin, umur dan rasio INW tidak meningkatkan resiko terjadinya cedera ACL. Penelitan dengan jumlah sampel yang lebih besar dan bersifat prospektif dapat memberikan hasil yang lebih representatif untuk mengetahui faktor resiko terjadinya cedera ACL. 


\section{REFERENSI}

1. Lyman S, Koulouvaris P, Sherman S, Do H, Mandl LA, Marx RG. Epidemiology of anterior cruciate ligament reconstruction: trends, readmissions, and subsequent knee surgery. JBJS. 2009;91(10):23212328.

2. Todd MS, Lalliss S, Garcia ES, DeBerardino TM, Cameron KL. The relationship between posterior tibial slope and anterior cruciate ligament injuries. The American journal of sports medicine. 2010;38(1):63-67.

3. Chambat P, Guier C, Sonnery-Cottet B, Fayard J-M, Thaunat M. The evolution of ACL reconstruction over the last fifty years. International orthopaedics. 2013;37(2):181-186.

4. Pappas E, Zampeli F, Xergia SA, Georgoulis AD. Lessons learned from the last 20 years of ACL-related in vivo-biomechanics research of the knee joint. Knee Surgery, Sports Traumatology, Arthroscopy. 2013;21(4):755-766.

5. Zaffagnini S, Grassi A, Serra M, Marcacci M. Return to sport after ACL reconstruction: how, when and why? A narrative review of current evidence. Joints. 2015;3(1):25.

6. Smith HC, Vacek P, Johnson RJ, et al. Risk factors for anterior cruciate ligament injury: a review of the literature-part 1: neuromuscular and anatomic risk. Sports health. 2012;4(1):69-78.

7. Görmeli CA, Görmeli G, Öztürk YB, Özdemir Z, Kahraman A. The Effect of The Intercondyler Notch Width Index on Anterior Cruciate Ligament Injuries: A Study on Groups with Unilateral and Bilateral ACL Injury. Orthopaedic journal of sports medicine.

2014;2(11_suppl3):2325967114S232 5900204.

8. Voos JE, Suero EM, Citak M, et al. Effect of tibial slope on the stability of the anterior cruciate ligamentdeficient knee. Knee Surgery, Sports Traumatology, Arthroscopy. 2012;20(8):1626-1631.

9. Feucht MJ, Mauro CS, Brucker PU, Imhoff $A B$, Hinterwimmer $S$. The role of the tibial slope in sustaining and treating anterior cruciate ligament injuries. Knee surgery, sports traumatology, arthroscopy. 2013;21(1):134-145.

10. Utzschneider S, Goettinger M, Weber $P$, et al. Development and validation of a new method for the radiologic measurement of the tibial slope. Knee Surgery, Sports Traumatology, Arthroscopy. 2011;19(10):1643-1648.

11. Lipps DB, Wilson AM, Ashton-Miller JA, Wojtys EM. Evaluation of different methods for measuring lateral tibial slope using magnetic resonance imaging. The American journal of sports medicine. 2012;40(12):2731-2736.

12. Khattak MJ, Umer M, Davis ET, Habib M, Ahmed M. Lower-limb alignment and posterior tibial slope in Pakistanis: a radiographic study. Journal of Orthopaedic Surgery. 2010;18(1):22-25.

13. El-Azab H, Glabgly P, Paul J, Imhoff AB, Hinterwimmer S. Patellar height and posterior tibial slope after openand closed-wedge high tibial osteotomy: a radiological study on 100 patients. The American journal of sports medicine. 2010;38(2):323-329.

14. Yue B, Varadarajan KM, Ai S, Tang T, Rubash HE, Li G. Differences of knee anthropometry between Chinese and white men and women. The Journal of arthroplasty. 2011;26(1):124-130.

15. Simon R, Everhart J, Nagaraja $H$, Chaudhari A. A case-control study of anterior cruciate ligament volume, tibial plateau slopes and intercondylar notch dimensions in ACL-injured knees. Journal of biomechanics. 2010;43(9):1702-1707. 
16. Hashemi J, Chandrashekar N, Gill B, et al. The geometry of the tibial plateau and its influence on the biomechanics of the tibiofemoral joint. The Journal of Bone and Joint Surgery. American volume. 2008;90(12):2724.

17. Yoga R, Sivapathasundaram N, Suresh C. Posterior slope of the tibia plateau in Malaysian patients undergoing total knee replacement. Malaysian Orthopaedic Journal. 2009;3(1):78-80.

18. Haddad B, Konan S, Mannan K, Scott G. Evaluation of the posterior tibial slope on MR images in different population groups using the tibial proximal anatomical axis. Acta Orthopadica Belgica. 2012;78(6):757.

19. Vyas S, Van Eck CF, Vyas N, Fu FH, Otsuka NY. Increased medial tibial slope in teenage pediatric population with open physes and anterior cruciate ligament injuries. Knee Surgery, Sports Traumatology, Arthroscopy. 2011;19(3):372-377.

20. Shultz SJ, Schmitz RJ, Benjaminse A, Collins M, Ford K, Kulas AS. ACL Research Retreat VII: An Update on Anterior Cruciate Ligament Injury Risk Factor Identification, Screening, and Prevention: March 19-21, 2015; Greensboro, NC. Journal of athletic training. 2015;50(10):1076-1093.

21. Keays S, Keays R, Newcombe P. Femoral intercondylar notch width size: a comparison between siblings with and without anterior cruciate ligament injuries. Knee Surgery, Sports Traumatology, Arthroscopy. 2016;24(3):672-679.

22. Al-Saeed O, Brown M, Athyal R, Sheikh M. Association of femoral intercondylar notch morphology, width index and the risk of anterior cruciate ligament injury. Knee Surgery, Sports Traumatology, Arthroscopy. 2013;21(3):678-682.

23. Laboute E, Savalli L, Puig P, et al. Analysis of return to competition and repeat rupture for 298 anterior cruciate ligament reconstructions with patellar or hamstring tendon autograft in sportspeople. Annals of physical and rehabilitation medicine. 2010;53(10):598-614. 